\title{
TOPA Quinone, a Kainate-like Agonist and Excitotoxin, Is Generated by a Catecholaminergic Cell Line
}

\author{
Timothy A. Newcomer, ${ }^{1}$ Paul A. Rosenberg, ${ }^{2}$ and Elias Aizenman ${ }^{1}$ \\ 'Department of Neurobiology, University of Pittsburgh School of Medicine, Pittsburgh, Pennsylvania 15261 and \\ 2Department of Neurology, Children's Hospital and Harvard Medical School, Boston, Massachusetts 02115
}

\begin{abstract}
The quinone derivative of 2,4,5-trihydroxyphenylalanine (TOPA) is a selective non-NMDA agonist and excitotoxin. While 3,4-dihydroxyphenylalanine (DOPA)-containing physiological solutions have been shown to generate TOPA and TOPA quinone (TOPA compounds), there have been no previous reports demonstrating the formation of this toxin in biological preparations. Here, using a pheochromocytoma catecholaminergic clonal cell line (PC12), we have identified TOPA compounds as by-products of catecholamine synthesis. PC12 cells incubated for $\mathbf{4 5}$ min with $\mathbf{3 0}$ $\mu \mathrm{M}$ tyrosine as a catecholamine precursor produced $1.0 \pm$ $0.2 \mathrm{pmol} / 10^{6}$ cells of total TOPA compounds. The formation of these compounds could be enhanced nearly twofold when the cells were stimulated with $56 \mathrm{~mm} \mathrm{KCl}$. Moreover, the addition of a DOPA decarboxylase inhibitor $(30 \mu \mathrm{M}$ NSD-1015) increased the formation of TOPA compounds in both the unstimulated and stimulated conditions to a maximum of $5.5 \pm 0.7 \mathrm{pmol} / 10^{6}$ cells after a $45 \mathrm{~min}$ incubation. A time-course analysis revealed that DOPA production above baseline levels coincided with the detectable generation of TOPA compounds. Finally, we observed an inhibition of TOPA compounds formation by $100 \mu \mathrm{m}$ reduced glutathione, suggesting that these catecholamine products are formed from the extracellular autoxidation of DOPA. We propose that TOPA quinone may be an underestimated component of catecholamine toxicity that could be partly responsible for the demise of neurons in several neurodegenerative disorders, including Parkinson's and Huntington's disease. In addition, TOPA quinone may represent the first identified selective non-NMDA agonist that may be synthesized in the brain.
\end{abstract}

[Key words: DOPA, TOPA quinone, non-NMDA, glutamatergic, excitotoxicity, catecholamine toxicity, PC12, HPLC]

Neuromelanin deposition within the cytoplasm of catecholamine-synthesizing neurons is indicative of nonenzymatic oxidative degradation of these substances (Graham, 1979). The ox-

\footnotetext{
Received Aug. 29, 1994; revised Oct. 13, 1994; accepted Oct. 17, 1994.

The advice and assistance of $\mathrm{F}$. DePietro and $\mathrm{K}$. Hartnett are gratefully acknowledged. We thank Dr. A. Tischler (Boston, MA) for the gift of PC 12 cells. This work was supported in part by NIH Grants NS26830, NS29365, NS31353, and NS32570. P.A.R. is an Established Investigator of the American Heart Association.

Correspondence should be addressed to Dr. Elias Aizenman, Department of Neurobiology, E1456 BST, University of Pittsburgh School of Medicine, Pittsburgh, PA 15261 .

Copyright 11995 Society for Neuroscience $0270-6474 / 95 / 153172-06 \$ 05.00 / 0$
}

idative processes present in these neurons are also likely to be responsible for the generation of reactive oxygen species as well as quinone and semiquinone catechol derivatives. These toxic substances may contribute to the pathogenesis of disorders affecting catecholaminergic neurons or their targets (Cohen et al., 1974; Graham, 1984; Youdim et al., 1993). Our laboratories have been investigating the toxic properties of the quinone derivative of 2,4,5-trihydroxyphenylalanine (TOPA), a proposed intermediate of 3,4-dihydroxyphenylalanine (DOPA) oxidation (Graham and Jeffs, 1977). We have demonstrated that at physiological $\mathrm{pH}$, TOPA rapidly oxidizes to TOPA quinone, a compound that is stable for hours in aqueous solutions (Rosenberg et al., 1991; Kano et al., 1993; Newcomer et al., 1993). TOPA quinone is a selective non-NMDA glutamatergic agonist that can elicit kainate-like electrical responses in neurons (Biscoe et al., 1976; Aizenman et al., 1990; Olney et al., 1990), as well as effectively displace $\left[{ }^{3} \mathrm{H}\right] \Lambda \mathrm{MP} \Lambda$ binding in rat striatum (Cha et al., 1991). In addition, excessive stimulation of non-NMDA receptors by TOPA quinone has been shown to be neurotoxic in vitro (Olney, 1990; Rosenberg et al., 1991; Aizenman et al., 1992; Skaper et al., 1993a,b).

In a recent study, we observed that DOPA in physiological salt solutions can readily autoxidize to form TOPA and TOPA quinone (Newcomer et al., 1993). This conversion was enhanced 10-fold by strong oxidizing conditions (Newcomer et al., 1995). Although these findings strongly suggest that TOPA quinone may be generated endogenously by DOPA-containing neurons, heretofore, no studies have shown this to be the case. In the present investigations, we have utilized a model catecholaminergic cell system, the PC12 cell line derived from a rat pheochromocytoma (Greene and Tischler, 1976), in order to begin to carefully evaluate the conditions necessary to produce TOPA quinone in vivo. The detection of TOPA quinone produced by this system would suggest that this metabolite could be important in a neurodegenerative cascade involving catecholaminergic nuclei or their targets.

\section{Materials and Methods}

Materials. TOPA, L-DOPA, L-tyrosine, $m$-hydroxybenzylhydrazine $2 \mathrm{HCl}$ (NSD-1015), and reduced glutathione were obtained from Sigma. Mobile phase reagents were HPLC grade, if offered, and obtained from Fisher Scientific, except for sodium 1-octanesulfonic acid (SOS; Eastman Kodak Company) and $\mathrm{HCl}$ (Ultrapure, J. T. Baker) Standard stock solutions of $1 \mathrm{mM}$ TOPA and $10 \mathrm{~mm}$ DOPA were prepared in $0.01 \mathrm{M} \mathrm{HCl}$, passed through a $0.22 \mu \mathrm{m}$ filter, and divided into $1.5 \mathrm{ml}$ microcentrifuge tubes for storage at $-80^{\circ} \mathrm{C}$. Single aliquots were thawed and used for generating standard curves for one day's experiments.

Cell culture. PC12 cells were growil on ral tail collagent-cuated 100 $\mathrm{mm}$ plastic tissue culture dishes in a growth medium consisting of $85 \%$ 
RPMI 1640 (Sigma), 10\% heat-inactivated horse serum (Sigma), 5\% fetal calf serum (Sigma), $50 \mu \mathrm{g} / \mathrm{ml}$ streptomycin, and $50 \mathrm{U} / \mathrm{ml}$ penicillin. Cultures were maintained at $37^{\circ} \mathrm{C}$ in an atmosphere of $95 \% \mathrm{O}_{2} / 5 \%$ $\mathrm{CO}_{2}$. Culture medium was replaced three times weekly. For experiments, cells were split and plated on collagen-coated $35 \mathrm{~mm}$ tissue culture dishes in the same growth medium. Two days after plating the medium was replaced and experiments were performed 24 hr later. During the course of our studies we noticed significant variability in our results if different plating densities were utilized. Similarly, many other groups have also reported that different plating densities of PC12 cells leads to variability in a number of assays (Lucas et al., 1979; Biocca et al., 1980; Tischler et al., 1983; Peppers and Holz, 1986; Vetter and Betz, 1989; Kozak and Yavin, 1992). Therefore, all results presented here were obtained from cultures plated at densities that resulted in 0.5 $1 \times 10^{\circ} \mathrm{cells} / \mathrm{dish}$ the day of the experiment. Platings that resulted in densities vutside this range were not used.

Measurement of production of TOPA compounds. Cells were washed twice with $1 \mathrm{ml}$ of Hanks' balanced salt solution (HBSS; $137 \mathrm{~mm} \mathrm{NaCl}$, $4 \mathrm{~mm} \mathrm{NaHCO}, 0.34 \mathrm{~mm} \mathrm{Na}_{2} \mathrm{HPO}_{4}, 5.37 \mathrm{~mm} \mathrm{KCl}, 0.44 \mathrm{~mm} \mathrm{KH} \mathrm{PO}_{4}$, $1.26 \mathrm{mM} \mathrm{CaCl}_{2}, 0.81 \mathrm{~mm} \mathrm{MgSO}_{4}, 5.60 \mathrm{mM}$ glucose, $25 \mathrm{~mm}$ HEPES, adjusted to $\mathrm{pH} 7.4$ with $\mathrm{NaOH}$ ), and incubated with $0.9 \mathrm{ml}$ of an exposure medium consisting of $30 \mu \mathrm{M}$ tyrosine in regular or high $\mathrm{K}^{+}$ HBSS, in the presence or absence of drugs. For the high $\mathrm{K}^{+}(56 \mathrm{~mm})$ exposure medium, there was a corresponding decrease in $\mathrm{NaCl}$ to maintain a constant osmolarity. The cultures were placed into the $37^{\circ} \mathrm{C}$ incubator for the appropriate time of exposure. Experiments were terminated by placing the culture dishes on ice and adding $0.1 \mathrm{ml}$ of $2 \mathrm{~N}$ $\mathrm{HCl}$ to each dish. 'The cells were then scraped from the dishes and the suspensions transferred to ice-chilled 1.5 microcentrifuge tubes. The tubes were sonicated for $10 \mathrm{sec}$ to ensure cellular disruption and spun at $12,000 \times g$ for $5 \mathrm{~min}$ at $4^{\circ} \mathrm{C}$. Two hundred microliters of the supernatant were passed through 5000 nominal molecular weight cutoff filter microcentrifuge tubes at $12,000 \times g$ for $15 \mathrm{~min}$ at $4^{\circ} \mathrm{C}$ and assayed for the presence of catecholamines. For all experiments, cell counts were performed on sister cultures that were treated similarly to the experimental cultures and detached with $0.25 \%$ trypsin.

Catecholamine analysis. HPLC procedures were similar to those previously described (Newcomer et al., 1993). Briefly, separation was achieved using a reverse-phase guard column and an analytical column ( $4.6 \mathrm{~mm}$ i.d. $\times 25 \mathrm{~cm}$ long, Rainin) packed with C18 modified silica particles $5 \mu \mathrm{m}$ in diameter. Samples $(25 \mu \mathrm{l})$ of solutions were intro duced into the column using a manual injector. The mobile phase comprised a mixture of $100 \mathrm{~mm}$ phosphoric acid, $0.1 \mathrm{mM} \mathrm{Na}_{2} \mathrm{EDTA}, 2.0$ $\mathrm{mm}$ SOS (with the $\mathrm{pH}$ adjusted from 2.4 to 3 with $\mathrm{NaOH}$ ) and 12-15\% (v/v) methanol. Compounds were measured with an electrochemical detector (Coulochem II, ESA) composed of dual coulometric porous graphite electrodes (model 5014, ESA) that followed a conditioning cell (model 5021, ESA). Electrode settings were adjusted to screen for TOPA compounds as follows: conditioning electrode $=-100 \mathrm{mV}$, electrode $1=-100 \mathrm{mV}$, and electrode $2=-350 \mathrm{mV}$ (Newcomer et al., 1993). Peak identity was established utilizing the following criteria: (1) retention time at various chromatography conditions as indicated in the results, (2) addition of authentic standard to increase peak size (spiking), and (3) electrochemical behavior of standard versus unknown at different electrode potentials. Quantification was performed by integrating the area under a peak relative to the baseline, and then calibrating with standard curves. The limit of sensitivity, defined as a signal-to-noise ratio $>2$, was 2.5 fmol for TOPA and TOPA quinone. DOPA was similarly measured as above, except using the following electrode settings: conditioning cell $=+150 \mathrm{mV}$, electrode $1=+150 \mathrm{mV}$, and $-350 \mathrm{mV}$.

\section{Results}

Our initial set of experiments were designed to investigate whether PC12 cells could produce TOPA and TOPA quinone, and whether these substances could be identified reliably by an HPLC assay (Newcomer et al., 1993). Working on the premise that a large amount of DOPA production would coincide with significant formation of TOPA compounds, PC12 cells were stimulated under conditions previously shown to be effective in generating DOPA (Lee et al., 1985). Cultures were thus exposed to an incubating medium consisting of the catecholamine precursor tyrosine $(30 \mu \mathrm{M})$ and the aromatic amino acid decarbox- ylase inhibitor NSD-1015 $(30 \mu \mathrm{M})$ in $56 \mathrm{~mm} \mathrm{~K}^{+}$HBSS. After a $45 \mathrm{~min}$ exposure, the incubation was terminated and the samples prepared for HPLC analysis. We began with chromatography conditions (Newcomer et al., 1993) that previously allowed us to separate TOPA and TOPA quinone from other catecholamine-related substances such as norepinephrine (NE), DOPA, epinephrine (EPI), 3,4-dihydroxyphenylacetic acid (DOPAC), methyl-tyrosine (M-TYR), dopamine (DA), and homovanillic acid (HVA). These conditions consisted of utilizing a mobile phase buffered to $\mathrm{pH} 3$ and containing $15 \%$ methanol (mobile phase A) and setting the electrodes at the detector at potentials (electrode $1=-100 \mathrm{mV}$ and electrode $2=-350 \mathrm{mV}$ ) that substantially diminish the signals produccd by NE, DOPA, EPI, DOPAC, M-TYR, DA, and HVA, but not by TOPA or TOPA quinone (Newcomer et al., 1993). Under these circumstances (Fig. 1, left), retention times for TOPA quinone and TOPA standards were, respectively, 6.1 and $7.4 \mathrm{~min}$. In addition, the typical dominant species of authentic TOPA solutions prepared at physiological $\mathrm{pH}$ is TOPA quinone (Newcomer et al., 1993). In the samples from the stimulated PC12 cells there were also two peaks with corresponding retention times. When the PC12 samples were mixed with equal parts of the standard (spiking), the corresponding peaks remain elevated while the other peaks in the samples were diminished.

To confirm the positive identification of TOPA quinone and TOPA, chromatography conditions were altered to further separate the peaks of interest from all other confounding peaks (Fig. 1 , right). Specifically, the $\mathrm{pH}$ of the mobile phase was lowered to 2.4 and the methanol concentration was decreased to $12 \%$ (mobile phase B). This resulted in an increased retention time for both TOPA and TOPA quinone $(10.0$ and $11.1 \mathrm{~min}$, respectively, Fig. 1, right). Using these conditions, the appearance and retention times of peaks derived from the unknown samples were identical to a standard of TOPA compounds that had been acidified in a similar fashion to the PC12 cell extract. This procedure had been previously shown to reduce a portion of TOPA quinone back to TOPA (Newcomer et al., 1993). These HPLC separation conditions were utilized for the analysis and quantification of TOPA compounds in PC12 cell samples throughout the remainder of this study. TOPA and TOPA-quinone always coexist as a tautomeric mixture in solution, with TOPA being the dominant species under acidic conditions, while the quinone predominates at physiological or alkaline $\mathrm{pH}$ levels (Newcomer et al., 1993). In addition, both these substances can be readily interconverted (Newcomer et. al., 1993). Therefore, in all subsequent quantification of our data, we have pooled the total amount of TOPA compounds detected in the experimental samples.

The next set of experiments were designed to define in more detail the various conditions for the production of TOPA compounds by PC12 cells (Fig. 2). Cultures incubated for $45 \mathrm{~min}$ in the presence of the precursor tyrosine $(30 \mu \mathrm{M})$ alone in HBSS generated a small but measurable amount of total TOPA compounds $\left(1.0 \pm 0.2 \mathrm{pmol} / 10^{6}\right.$ cells; mean $\left.\pm \mathrm{SEM}, n=4\right)$. Since it seemed reasonable to assume that TOPA compounds were directly derived from DOPA oxidation (Graham and Jeffs, 1977; Newcomer et al., 1993), incubation conditions were altered to either increase DOPA synthesis or to allow for its accumulation. The DOPA-synthesizing enzyme tyrosine hydroxylase is activated by phosphorylation via several $\mathrm{Ca}^{2+}$-dependent protein $\mathrm{ki}$ nases (Funakoshi et al., 1991). Therefore, when PC12 cells are depolarized with high $\mathrm{K}^{+}$solutions, the ensuing $\mathrm{Ca}^{2+}$ entry via 
Mobile Phase A

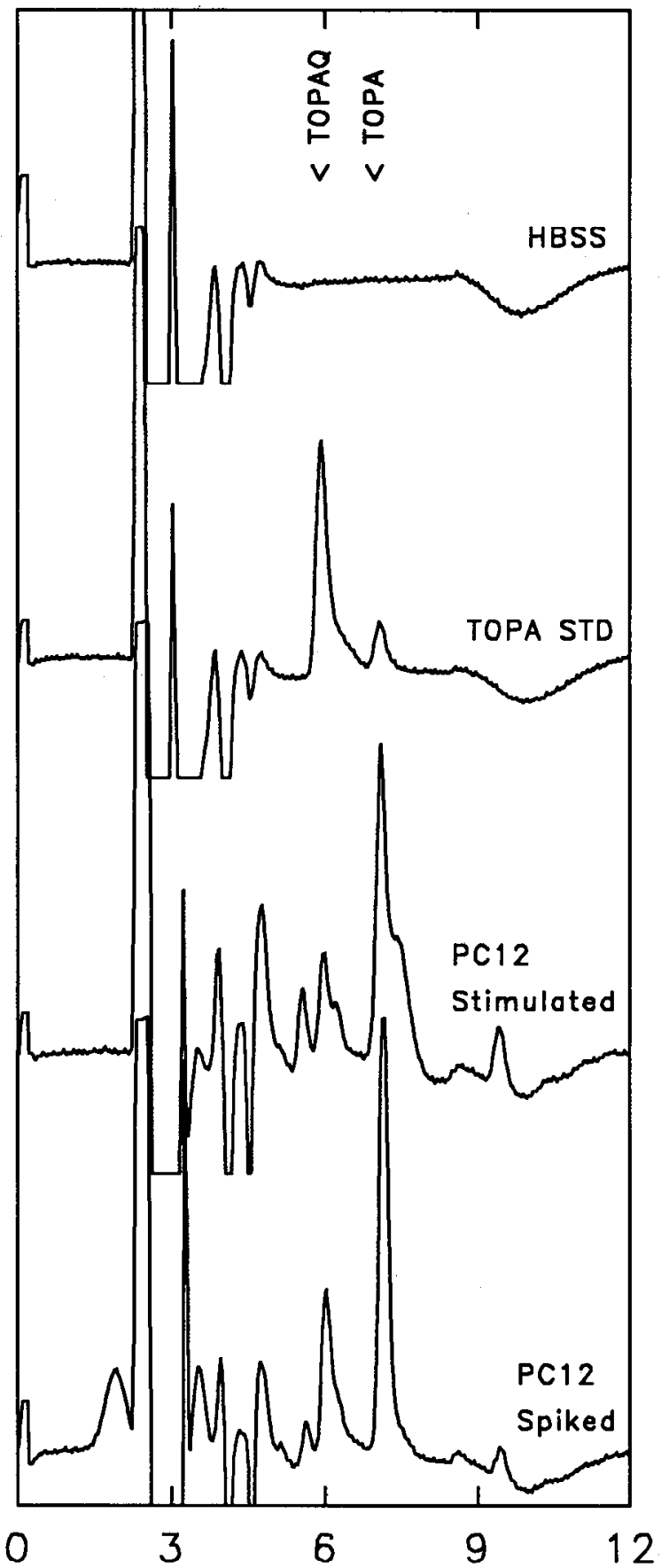

Mobile Phase B

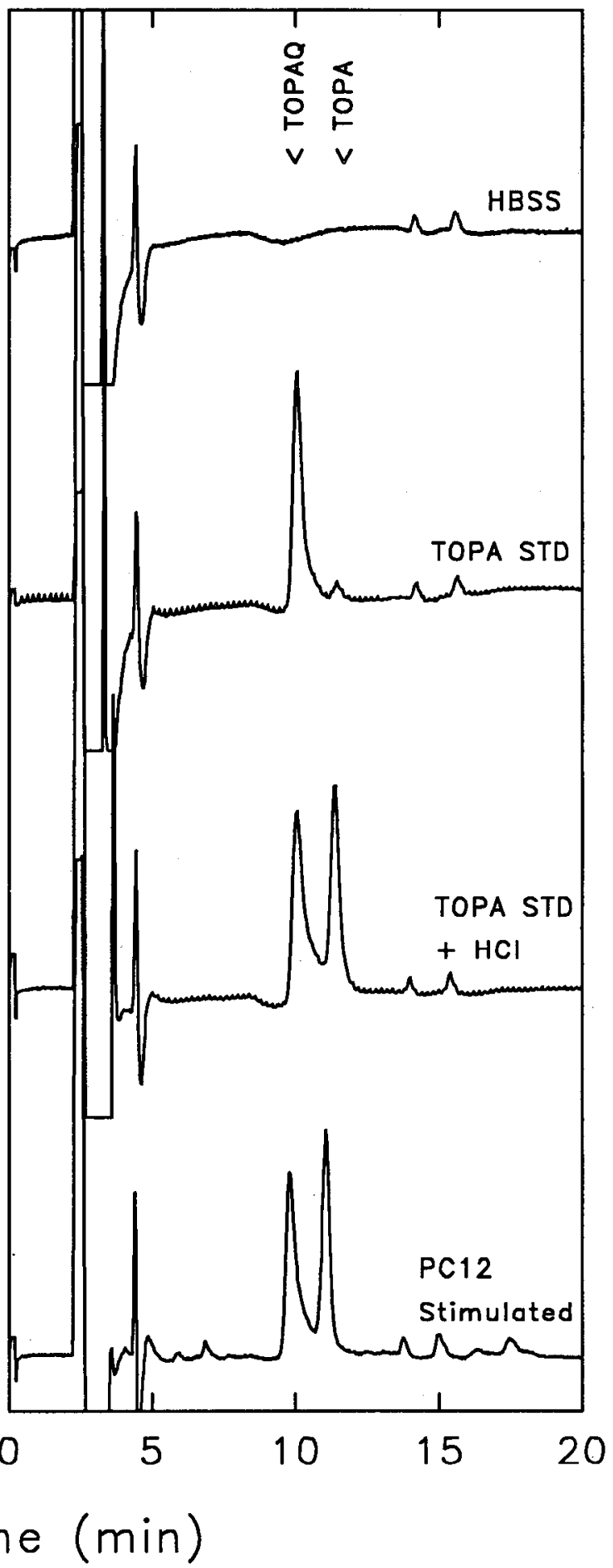

Figure 1. Identification of TOPA and TOPA quinone in PC12 cells. Shown on the left are four chromatograms obtained using mobile phase A (pH 3 and $15 \%$ methanol). HBSS, a chromatogram of an incubation medium blank containing $30 \mu \mathrm{M}$ tyrosine and $30 \mu \mathrm{M}$ NSD in a high $\mathrm{K}^{+}$-HBSS. TOPA STD, TOPA diluted to $30 \mathrm{nM}(0.75 \mathrm{nmol})$ in the HBSS incubation medium at physiological $\mathrm{pH}$ showing the typical dominant species as TOPA quinone; retention times for TOPA quinone and TOPA are 6.1 and $7.4 \mathrm{~min}$, respectively. PC 12 Stimulated, extracts from PC12 cells exposed to the above incubation medium for $45 \mathrm{~min}$ and then exposed to $\mathrm{HCl}$ have two corresponding peaks with comparable retention times to the standard. PC12 Spiked, a 50:50 mixture of the TOPA standard, and the PC12 cells sample kept the corresponding peaks in the sample elevated without broadening them while all other peaks were diminished. The right panel displays four chromatograms obtained using mobile phase $B$ (pH $2.4,12 \%$ methanol). HBSS, TOPA STD, and PC12 Stimulated, chromatograms obtained from samples similar to those described above. TOPA STD + HCl, a $50 \mathrm{nM}$ TOPA standard was acidified in a similar matter as the PC12 samples, demonstrating how a portion of TOPA quinone is converted back to TOPA; the standard now parallels the appearance and retention times of the PC12 cell sample. 


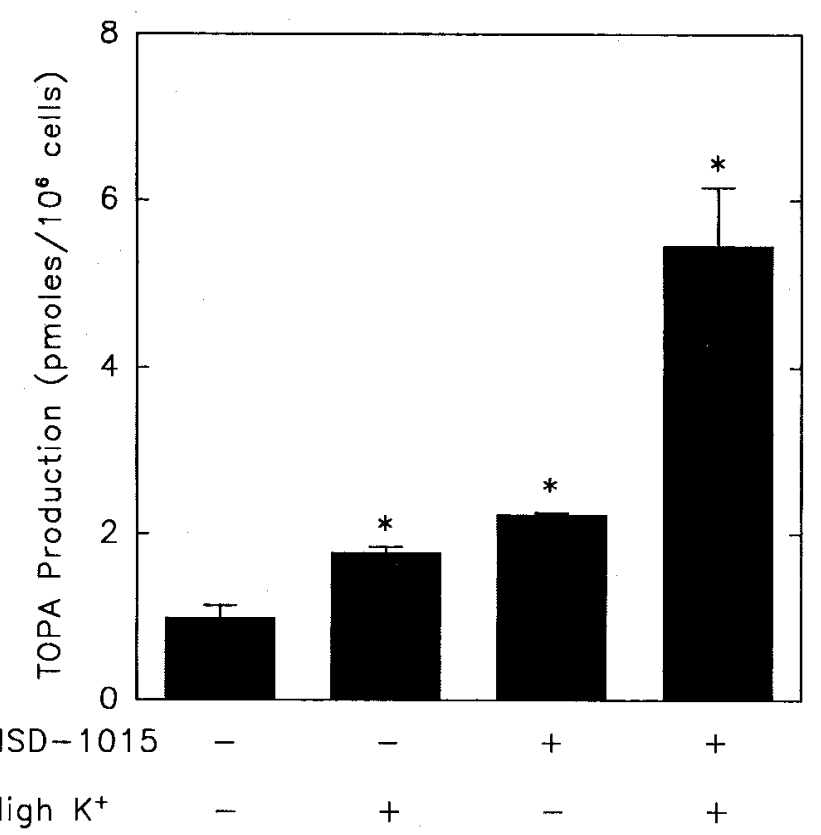

Figure 2. Conditions for formation of TOPA compounds in $\mathrm{PC} 12$ cells. PC12 cells were incubated for $45 \mathrm{~min}$ in a HBSS or high $\mathrm{K}^{+}$ HBSS containing $30 \mu \mathrm{M}$ tyrosine in the presence and absence of $30 \mu \mathrm{M}$ NSD-1015. Total TOPA compounds measured are expressed as mean \pm SEM of three to six experiments. The asterisk $\left({ }^{*}\right)$ indicates a oneway analysis of variance revealed a significant difference among groups $(p<0.001 ; F=13.6)$. Post hoc comparisons among selected groups revealed significant differences $(p<0.005)$ between treatment groups and control.

voltage-gated channels results in a rapid, increased activation of tyrosine hydroxylase (Yanagihara et al., 1984; Nose et al., 1985). Under these conditions, TOPA compounds production was increased nearly twofold in these cells. Moreover, this production was similarly increased by utilizing a DOPA decarboxylase inhibitor ( $30 \mu \mathrm{M}$ NSD-1015), and, in fact, the combination of both a high $\mathrm{K}^{+}$stimulation and decarboxylase inhibition resulted in a fivefold increase in TOPA production after a $45 \mathrm{~min}$ incubation (Fig. 2).

The temporal relationship between DOPA synthesis and production of TOPA compounds was next examined. PC12 cells were exposed to an incubating medium to optimally produce DOPA, containing $30 \mu \mathrm{M}$ tyrosine, $30 \mu \mathrm{M}$ NSD-1015, and high $\mathrm{K}^{+}$. The incubations were terminated at $0,15,30,45$, and 60 min, and the PC12 samples analyzed for total DOPA and TOPA compounds (Fig. 3). Some DOPA was detectable at time 0 , which reveals the basal levels of this substance that these cells can produce. The production of DOPA did not significantly increase over baseline until $30 \mathrm{~min}$ of incubation, at which time TOPA compounds could be detected for the first time. The production of DOPA and TOPA compounds continued to increase with time. After $1 \mathrm{hr}, 12.9 \pm 0.9 \mathrm{pmol} / 10^{6}$ cells $(n=6)$ of TOPA compounds could be measured, which represents approximately $1 \%$ of the amount of DOPA compounds that were produced.

It has been reported that the majority of DOPA is found extracellularly during incubation conditions similar to those described above (Greene and Rein, 1977). In addition, the aforementioned lag in the detection of TOPA compounds that coincides with DOPA production above baseline levels suggests that TOPA compounds may be formed from the autoxidation of

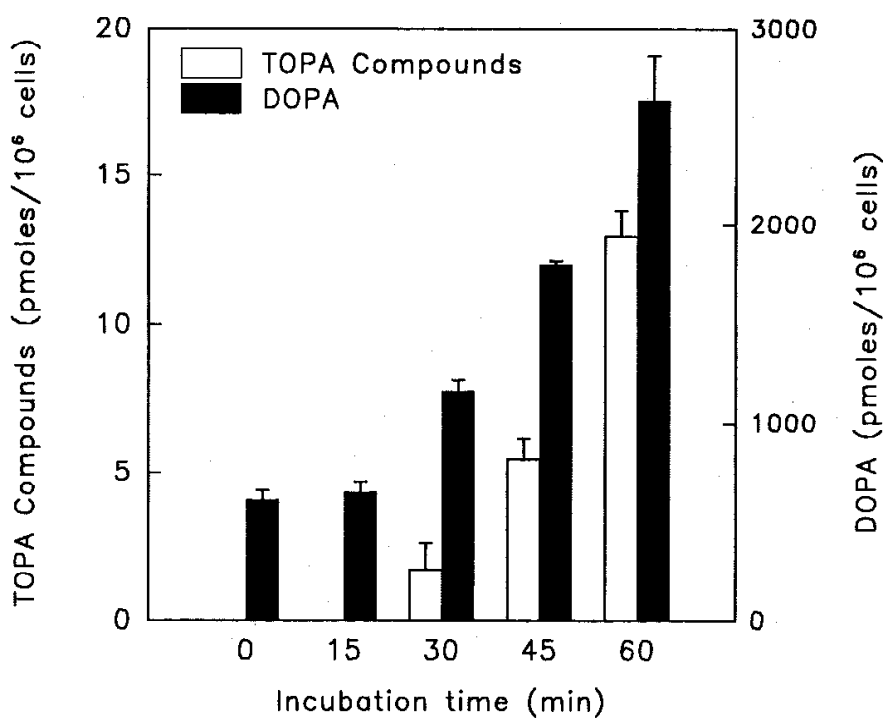

Figure 3. Time course of formation of DOPA and TOPA compounds. PC12 cells were incubated in a medium containing $30 \mu \mathrm{M}$ tyrosine and $30 \mu \mathrm{M}$ NSD-1015 in high $\mathrm{K}^{+}$-HBSS. At the indicated time points, the incubation was stopped and the resultant total DOPA and TOPA compounds measured. Shown are mean \pm SEM of three to six experiments per time point.

extracellular DOPA. This possibility was tested by utilizing reduced GSH in the incubation media, as this antioxidant does not permeate cell membranes and is not significantly transported into most cells (Meister, 1994). GSH, as well as other reducing agents such as dithiothreitol, cannot only prevent TOPA quinone formation from TOPA (Rosenberg et al., 1991; Aizenman et al., 1992), but can also inhibit TOPA production from DOPA in physiological salts solutions (Newcomer and Aizenman, unpublished observation). PC12 cells were incubated for $60 \mathrm{~min}$ in a medium containing $30 \mu \mathrm{M}$ tyrosine and $30 \mu \mathrm{M}$ NSD-1015 in high $\mathrm{K}^{+}$HBSS in the presence and absence of $100 \mu \mathrm{M}$ GSH. Although this thiol did not alter the accumulation of DOPA in the cultures, it completely blocked the production of TOPA compounds (Fig. 4).

\section{Discussion}

These experiments demonstrate, for the first time, that the excitotoxin TOPA quinone, as well as its precursor TOPA, can be formed from a cellular source of DOPA. Even PC12 cells presented only with the substrate tyrosine were capable of producing TOPA compounds as by-products of catecholamine synthesis. This production was increased when the PC12 cells were stimulated with high $\mathrm{K}^{+}$HBSS to increase tyrosine hydroxylase activity and thereby increase DOPA synthesis along with its release. Furthermore, when DOPA was allowed to accumulate by preventing its degradation with NSD-1015, there was a further increased formation of TOPA compounds in both unstimulated and stimulated conditions.

It is noteworthy that PC12 cells represent a simple model system, and it will be important to determine whether similar results can be obtained with either cultured mesencephalic neurons or in more intact systems. Nevertheless, evidence from this study strongly suggests that TOPA compounds form following the extracellular autoxidation of DOPA. It is likely that baseline DOPA levels detected are mostly intracellular where formation of TOPA compounds would be expected to be inhibited by in- 


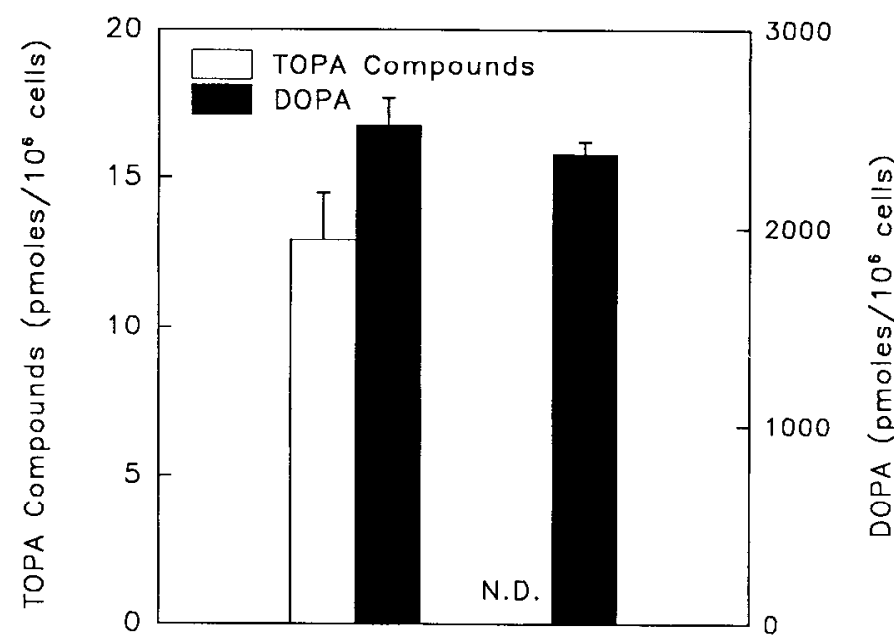

$100 \mu \mathrm{M} \mathrm{GSH}$ $+$

Figure 4. GSH prevents the production of TOPA compounds. $\mathrm{PC} 12$ cells were incubated in a medium containing $30 \mu \mathrm{M}$ tyrosine and 30 $\mu \mathrm{M}$ NSD-1015 in high $\mathrm{K}^{+}$-HBSS in the presence and absence of 100 $\mu \mathrm{M}$ GSH. After $60 \mathrm{~min}$, the incubation was terminated and the resultant total content of DOPA and TOPA compounds measured. Values are expressed as mean \pm SEM of four to six experiments. N.D.. not detectable.

tracellular antioxidants. Upon continued stimulation, any DOPA that accumulates extracellularly (Greene and Rein, 1977) can autoxidize to generate TOPA and TOPA quinone, a reaction that can be inhibited by GSH. Therefore, it is readily apparent from our results that TOPA and TOPA quinone are not stored or accumulated inside cells, since extracellular GSH completely abolished their detection. It is possible, nonetheless, that GSH could be reacting with the TOPA compounds after they are formed and producc adducts, thereby appearing as if oxidation had not taken place. In fact, GSH has been reported to react with semiquinone free radicals and ortho-quinones (Mans et al., 1992), although it does not react with catechols (Mans et al., 1992), and, thus, at least some unoxidized TOPA would still be expected to be present in the GSH-containing media under any circumstances.

The demonstration of the formation of TOPA compounds in a catecholaminergic cell line in culture suggests that these substances could be formed in the brain. It is noteworthy that DOPA itself has been shown to be released from nicotine-stimulated striatal slices obtained from rats (Misu et al., 1990) and can be detected after $\mathrm{K}^{+}$-evoked release in rat striatum by microdialysis (Nakamura et al., 1992). It is reasonable to think that TOPA compounds could be formed from these extracellular DOPA sources in a similar manner to that reported in this study, especially in an oxidative environment (Newcomer et al., 1995). Such redox conditions could exist in some pathological states and, in fact, have been associated with the etiology of disorders such as Parkinson's disease (Jenner et al, 1992; Olanow, 1992). Our aforementioned results with GSH are also interesting in light of its known association with cellular protection systems (Meister, 1994). For example, a glutathione deficiency has been proposed to be associated wilh mitochondrial damage or poisoning, leading to oxidative stress (Jain et al., 1991; Mithöfer et al., 1992). Moreover, a nigral glutathione deficit has been implicated in the pathogenesis of Parkinson's disease (Perry et al.,
1982; Sofic et al., 1992). GSH has further been shown to be released from neurons in brain slices from rats (Zängerle et al., 1992), suggesting an extracellular antioxidant role for this substance. Hence, any DOPA present intracellularly or extracellularly during conditions when tissue antioxidant defenses are compromised may lead to the formation of TOPA compounds.

It is of special interest that there have been no previous reports of a brain-derived agonist specific for non-NMDA glutamatergic receptors. However, there is evidence that points to the specific involvement of non-NMDA receptors in playing a role in certain neurodegenerative disorders such as global cerebral ischemia (Sheardown et al., 1990), motor neuron disease (Couratier et al., 1993; Shaw ct al., 1994), neurolathyrism (Olney et al., 1976; Spencer et al., 1986; Bridges et al., 1989), and mussel poisoning (Perl et al., 1990; Teitelbaum et al., 1990). Furthermore, it has been clearly demonstrated that activation of non-NMDA receptors in cultured neurons and brain slices can lead to excitotoxic cell death (Koh et al., 1990; Garthwaite and Garthwaite, 199 (a,b). Of interest, it has been observed that a prior lesion of the substantia nigra protects striatal neurons from transient ischemia (Globus et al., 1987), potentially linking a catecholaminergic system with a lesion that is normally associated with glutamate toxicity (Rothman and Olney, 1986). It is thus possible that the generation of TOPA quinone by dopaminergic cells could render neighboring somata or afferent projection neurons vulnerable to excitotoxic injury via selective activation of nonNMDA receptors.

\section{References}

Aizenman E, White WF, Loring RH, Rosenberg PA (1990) A 3,4dihydroxyphenylalanine oxidation product is a non- $N$-methyl-D-aspartate glutamatergic agonist in rat cortical neurons. Neurosci Lett $116: 168-171$

Aizenman E, Boeckman FA, Rosenberg PA (1992) Glutathinne prevents 2,4,5-trihydroxyphenylalanine excitotoxicity by maintaining it in a reduced, non-active form. Neurosci Lett 116:168-171.

Biocca S, Levi A, Calissano P (1980) Cell density modulates receptor mediated internalization of nerve growth factor in pheochromocytoma cells. J Recept Res 1:373-387.

Biscoe TJ, Evans RH, Headley PM, Martin MR, Watkins JC (1976) Structure-activity relations of excitatory amino acids on frog and rat spinal neurones. Br J Pharmacol 58:373-382.

Bridges RJ, Stevens DR, Kahle JS, Nunn PB, Kadri M, Cotman C (1989) Structure-function studies on $\mathrm{N}$-oxalo-diaminocarboxylic acids and excitatory amino acid receptors: evidence that B-L-ODAP is a selective non-NMDA agonist. J Neurosci 9:2073-2079.

Cha JJ, Dure LS IV, Sakurai SY, Penney JB, Young AP (1991) 2,4,5Trihydroxyphenylalanine (6-hydroxy-DOPA) displaces [ $\left.{ }^{3} \mathrm{H}\right] A M P A$ binding in rat striatum. Neurosci Lett 132:55-58.

Cohen G, Heikkila RE, McNamee D (1974) The generation of hydrogen peroxide, superoxide radical and hydroxyl radical by 6 hydroxy dopamine, dialuric acid and related cytotoxic agents. J Biol Chem 249:2447-2452.

Couratier P, Hugon J, Sindou P, Vallat JM, Dumas M (1993) Cell culture evidence for neuronal degeneration in amyotrophic lateral sclerosis being linked to AMPA/kainate receptors. Lancet 341:265-268.

Funakoshi H, Okuno S, Fujisawa H (I991) Different effects on activity caused by phosphorylation of tyrosine hydroxylase at serine 40 by three multifunctional protein kinases. J Biol Chem 266:15614-15620.

Garthwaite G, Garthwaite J (1991a) AMPA neurotoxicity in rat cerebellar and hippocampal slices: histological evidence for three mechanisms. Eur J Neurosci 3:715-728.

Garthwaite G, Garthwaite J (1991b) Mechanisms of AMPA neurotoxicity in rat brain slices. Eur J Neurosci 3:729-736.

Globus MY-T, Ginsberg MD, Dietrich WD, Busto R, Scheinberg P (1987) Substantia nigra lesion protects against ischemic damage in the striatum. Neurosci Lett 80:251-256.

Graham DG (1979) On the origin and significance of neuromelanin. Arch Pathol Lab Med 103:359-362. 
Graham DG (1984) Catecholamine toxicity: a proposal for the molecular pathogenesis of manganese neurotoxicity and Parkinson's disease. Neurotoxicology 5:83-95.

Graham DG, Jeffs PW (1977) The role of 2,4,5-trihydroxyphenylalanine in melanin biosynthesis. J Biol Chem 252:5729-5734.

Greene LA, Rein G (1977) Short-term regulation of catecholamine biosynthesis in a nerve growth factor responsive clonal line of rat pheochromocytoma cells. J Neurochem 30:549-555.

Greene LA, Tischler AS (1976) Establishment of a noradrenergic clonal line of rat adrenal pheochromocytoma cells which respond to nerve growth factor. Proc Natl Acad Sci USA 73:2424-2428.

Jain A, Mårtensson J, Stole E, Auld PAM, Meister A (1991) Glutathione deficiency leads to mitochondria damage in brain. Proc Natl Acad Sci USA 88:1913-1917.

Jenner P, Dexter DT, Sian J, Schapira AHV, Marsden CD (1992) Oxidative stress as a cause of Parkinson's disease. Ann Neurol 32:S82S87.

Kano K, Mori T, Uno B, Goto M, Ikeda T (1993) Characterization of topa quinone. Biochem Biophys Acta 1157:324-331.

Koh J, Goldberg MP, Hartley DM, Choi DW (1990) Non-NMDA receptor mediated neurotoxicity in cortical culture. J Neurosci 10:693705 .

Kozak A, Yavin E (1992) Isolation and characterization by cell density adjustment of a $\mathrm{PC} 12$ pheochromocytoma variant with altered $\mathrm{Ca}^{2+}$ homeostasis. J Mol Neurosci 3:203-212.

Lee KY, Seeley PJ, Müller TH, Helmer-Matyjek E, Sabban E, Goldstein M, Greene LA (1985) Regulation of tyrosine hydroxylase phosphorylation in $\mathrm{PC} 12$ pheochromocytoma cells by elevated $\mathrm{K}^{+}$and nerve growth factor. Mol Pharmacol 28:220-228.

Lucas CA, Edgar D, Thoenen H (1979) Regulation of tyrosine hydroxylase and choline acetyltransferase activities by cell density in the PC12 rat pheochromocytoma cell line. Exp Cell Res 121:79-86.

Mans DRA, Lafleur MVM, Westmijze EJ, Horn IR, Bets D, Schuurhuis G J, Lankelma J, Retèl J (1992) Reactions of glutathione with the catechol, the ortho-quinone and the semi quinone free radical of etoposide. Biochem Pharmacol 43:1761-1768.

Meister A (1994) Glutathione, ascorbate, and cellular protection. Cancer Res [Suppl] 54:1969s-1975s.

Misu Y, Goshima Y, Nakamura S, Kubo T (1990) Nicotine releases stereoselectively and $\mathrm{Ca}^{2+}$-dependently endogenous 3,4-dihydroxyphenylalanine from rat striatal slices. Brain Res 520:334-337.

Mithöfer K, Sandy MS, Smith MT, Di Monte D (1992) Mitochondrial poisons cause depletion of reduced glutathione in isolated hepatocytes. Arch Biochem Biophys 295:132-136.

Nakamura S, Goshima Y, Yue JL, Misu Y (1992) Transmitter-like basal and $\mathrm{K}^{+}$-evoked release of 3,4-dihydroxyphenylalanine from striatum in conscious rats studied by microdialysis. J Neurochem 58:270-275.

Newcomer TA, Palmer AM, Rosenberg PA, Aizenman E (1993) Nonenzymatic conversion of 3,4-dihydroxyphenylalanine to $2,4,5$ tri hydroxyphenylalanine and 2,4,5-trihydroxyphenylalanine quinone in physiological solutions. J Neurochem 61:911-920.

Newcomer TA, Rosenberg PA, Aizenman E (1995) Iron-mediated oxidation of 3,4-dihydroxyphenylalanine to an excitotoxin. J Neurochem, in press.

Nose PS, Griffith LC, Schulman H (1985) $\mathrm{Ca}^{2+}$-dependent phosphorylation of tyrosine hydroxylase in PC12 cells. J Cell Biol 101:11821190.

Olanow CW (1992) An introduction to the free radical hypothesis in Parkinson's disease. Ann Neurol 32:S2--S9.
OIney JW, Misra CH, Rhee V (1976) Brain and retinal damage from the lathyrus excitotoxin, $\beta-N$-oxalyl- $\mathrm{L}-\alpha, \beta$-dianinopropionic acid (ODAP). Nature 264:659-661

Olney JW, Zorumski CF, Stewart GR, Price MT, Wang G, Labruyere J (1990) Excitotoxicity of L-DOPA and 6-OH-DOPA: implications for Parkinson's and Huntington's diseases. Exp Neurol 108:269-272.

Peppers SC, Holz RW (1986) Catecholamine secretion from digitonintreated PC12 cells. Effects of $\mathrm{Ca}^{2+}$, ATP, and protein kinase $\mathrm{C}$ activators. J Biol Chem 261:14665-14669.

Perl TM, Bedard L, Kostatsky T, Hockin IC, Todd ECD, Remis RM (1990) An outbreak of toxic encephalopathy caused by eating mussels contaminated with domoic acid. N Engl J Med 322:1775-1780.

Perry TL, Godin DV, Hansen S (1982) Parkinson's disease: a disorder due to nigral glutathione deficiency? Neurosci Lett 33:305-310.

Rosenberg PA, Loring R, Xie Y, Zaleskas V, Aizenman E (1991) 2,4,5Trihydroxyphenylalanine in solution forms a non- $N$-methyl-D-aspartate glutamatergic agonist and neurotoxin. Proc Natl Acad Sci USA 88:4865-4869.

Rothman SM, Oiney JW (1986) Glutamate and the pathophysiology of hypoxic-ischemic brain damage. Anal Neurol 19:105-111.

Shaw PJ, Chinnery RM, Ince PG (1994) Non-NMDA receptors in motor neuron disease (MND): a quantitative autoradiographic study in spinal cord and motor cortex using $\left[{ }^{3} \mathrm{H}\right] \mathrm{CNQX}$ and $\left[{ }^{3} \mathrm{H}\right] \mathrm{kainate}$. Brain Res 655:186-194.

Sheardown MJ, Nielsen, EO, Hansen AJ, Jacobsen P, Honoré T (1990) 2,3-Dihydroxy-6-nitro-7-sulfamoyl-benzo(F)quinoxaline: a neuroprotectant for cerebral ischemia. Science 247:571-574.

Skaper SD, Facci L, Schiavo N, Vantini G, Moroni F, Dal Taso R, Leon A (1993a) Characterization of 2,4,5-trihydroxyphenylalanine neurotoxicity in vitro and protective effects of ganglioside GM1: implications for Parkinson's disease. J Pharmacol Exp Ther 263:14401446.

Skaper SD, Negro A, Facci L, Dal Taso R (1993b) Brain-derived neurotrophic factor selectively rescues mesencephalic dopaminergic neurons from 2,4,5-trihydroxyphenylalanine-induced injury. J Neurosci Res 34:478-487.

Sofic E, Lange KW, Jellinger K, Riederer P (1992) Reduced and oxidized glutathione in the substantia nigra of patients with Parkinson's disease. Neurosci Lett 142:128-130.

Spencer PS, Ludolph A, Dwivedi MP, Roy DN, Hugon J, Schaumburg $\mathrm{HH}$ (1986) Lathyrism: evidence for the role of the excitatory amino acid BOAA. Lancet ii: 1066-1067.

Teitelbaum JS, Zatorre RJ, Carpenter S, Gendron D, Evans AC, Gjedde A, Cashman NR (1990) Neurologic sequelae of domoic acid intoxication due to the ingestion of contaminated mussels. N Engl J Med 322:1781-1787.

Tischler AS, Perlman RL, Morse GM, Sheard BE (1983) Glucocorticoids increase catecholamine synthesis and storage in PC12 pheochromocytoma cell cultures. J Neurochem 40:364-370.

Vetter B, Betz H (1989) Expression of synaptophysin in the rat pheochromocytoma cell line PC12. Exp Cell Res 184:360-366.

Yanagihara N, Tank AW, Weiner N (1984) Relationship between activation and phosphorylation of tyrosine hydroxylase by $56 \mathrm{mM} \mathrm{K}^{+}$in PC12 cells in culture. Mol Pharmacol 26:141-147.

Youdim MBH, Ben-Shachar D, Eshel G, Finberg JPM, Reiderer P (1993) The neurotoxicity of iron and nitric oxide. Adv Neurol 60: 259-265.

Zängerle L, Cuénod M, Winterhalter KH, Do KQ (1992) Screening of thiol compounds: depolarization-induced release of glutathione and cysteine from rat brain slices. J Neurochem 59:181-189. 